\title{
COMPREENDENDO A INFLUÊNCIA DO HOME CARE NA DINÂMICA FAMILIAR À LUZ DO MODELO CALGARY
}

\author{
Roberto Corrêa Leite ${ }^{1}$ \\ ${ }^{1}$ Mestre em Enfermagem. Faculdade Israelita de \\ Ciências da Saúde Albert Einstein (FICSAE)
}

INTRODUÇÃO: Home Care $(H C)$ tem se mostrado importante para a reabilitação do indivíduo que vivencia a doença crônica, com melhora na qualidade de vida e redução de novas hospitalizações. No entanto, as interações entre os membros familiares e profissionais podem influenciar e alterar significativamente a dinâmica familiar. Neste contexto, a utilização do Modelo Calgary de Avaliação da Família (MCAF) possibilita estabelecer um relacionamento terapêutico entre a família e o profissional, o entendimento do contexto em que estes estão inseridos e um adequado planejamento para 0 cuidado. OBJETIVO: Compreender a influência do Home Care na dinâmica familiar da criança/adolescente doente à luz do Modelo Calgary. MÉTODO: Estudo qualitativo, tendo o Interacionismo Simbólico e o MCAF, como referenciais teóricos e a Análise Qualitativa de Conteúdo Convencional como referencial metodológico. Aprovado pelo CEP do Hospital Israelita Albert Einstein (CAAE:63242316.6.0000.0071), realizado com 14 cuidadores familiares de crianças/adolescentes entre dois e 16 anos de idade, em internação domiciliar, atendidos por uma empresa privada de $\mathrm{HC}$ em Campinas (SP). Os dados foram coletados por meio de entrevista semiestruturada. RESULTADOS: A categoria Vivenciando o impacto do Home Care na rotina da família revelou que o contexto domiciliar é alterado e adaptado às regras do $H C$, devido à interferência na rotina familiar, impactando na liberdade, privacidade e segurança da família. Esta passa a ressignificar o lar diante das demandas de atendimento, esforçando-se para se adaptar às modificações provocadas pelo sistema, movimento também permeado pela constante preocupação com a segurança do filho. Este cenário é marcado por interações e ações complexas, que evidenciam as fragilidades e fortalezas da família e as inúmeras estratégias para manter-se firme com o propósito de compartilhar o cuidado. CONSIDERAÇÕES FINAIS: O cuidado em $H C$ altera a dinâmica familiar, exigindo uma reorganização estrutural, desenvolvimental e funcional 
da família. Reiteramos a importância da incorporação do MCAF na prática do cuidado domiciliar, como ferramenta para conhecer, avaliar e favorecer 0 vínculo com a família ao propor intervenções baseadas em suas necessidades.

Palavras-chave: Assistência domiciliar. Cuidadores. Enfermagem pediátrica. 